\title{
Percent Change From Baseline in Sum of Volume
}

National Cancer Institute

\section{Source}

National Cancer Institute. Percent Change From Baseline in Sum of Volume. NCI

Thesaurus. Code C112372.

The most recently recorded sum of volumes minus the baseline sum of volumes divided by the baseline sum of volumes, multiplied by 100 . 